\title{
Caracterização das Fibras Musculares do Músculo Semitendinosus de Bezerros Mestiços Angus-Nelore Recebendo Somatotropina Bovina Recombinante (rbST) até a Desmama ${ }^{1}$
}

\author{
Rafael da Costa Cervieri ${ }^{2}$, Mário De Beni Arrigoni ${ }^{3}$, Luis Arthur Loyola Chardulo ${ }^{4}$, Antônio \\ Carlos Silveira ${ }^{5}$, Henrique Nunes de Oliveira ${ }^{6}$, Cyntia Ludovico Martins ${ }^{7}$, Maeli Dal Pai Silva ${ }^{8}$
}

RESUMO - Objetivando-se estudar o efeito da somatotropina bovina recombinante (rbST) sobre a freqüência de distribuição e o diâmetro das fibras musculares do músculo Semitendinosus, 36 bezerros mestiços 1⁄2Angus-Nelore, com idade inicial de $63 \pm 17$ dias e pesando 76,8 $\pm 14,7 \mathrm{~kg}$, criados em pastagem de Brachiaria decumbens e suplementados em creep feeding, foram submetidos a dois tratamentos até a desmama (217 dias): 18 bezerros receberam 1,4 mg/kg de rbST (Boostin ${ }^{\circledR}$ ) a cada 14 dias e 18 receberam solução salina (controle). As amostras de músculo foram coletadas aos 117 (biópsia) e aos 217 dias de idade, quando foram abatidos cinco animais por tratamento. Os animais suplementados apresentaram maior diâmetro para as fibras do tipo glicolítica de contração rápida (FG) aos 117 dias e tendência de aumento aos 217 dias e não diferiram em relação ao grupo controle quanto ao diâmetro das fibras oxidativas-glicolíticas de contração rápida (FOG) e oxidativas de contração lenta (SO) e à frequência de FG, FOG e SO aos 117 e 217 dias de idade. Independentemente da aplicação de rbST, houve significativo aumento do diâmetro das fibras SO e FOG, tendência de aumento de diâmetro das fibras FG, maior frequência de SO e redução da frequência de FG entre 117 e 217 dias de idade. A utilização de somatotropina exógena possibilitou maior hipertrofia das fibras musculares brancas de contração rápida em bezerros suplementados em creep feeding durante a fase de cria, sem interferir na frequência de distribuição dos tipos de fibras no músculo Semitendinosus.

Palavras-chave: creep feeding, crescimento, superprecoce

\section{Characterization of Semitendinosus Muscle Fibers in Pre-Weaning Angus-Nellore Crossbred Calves Receiving Recombinant Bovine Somatotropin (rbST)}

\begin{abstract}
The objective of this experiment was to study the effect of the recombinant bovine somatotropin (rbST) on the percentage distribution and diameter of semitendinosus muscle fibers. Thirty-six $1 / 2$ Angus-Nellore crossbred bull calves, $63 \pm 17$ days old and weighting $76.8 \pm 14.7 \mathrm{~kg}$, raised in Brachiaria decumbens pastures and creep fed, were assigned to one of two treatments until weaning (217 days): eighteen calves received $1.4 \mathrm{mg} / \mathrm{kg}$ of rbST (Boostin ${ }^{\circledR}$ ) every 14 days and eighteen control calves received saline solution. Muscle samples were taken at 117 trough biopsy and at 217 days old when five animals from each treatment were slaughtered. The rbST-treated calves had greater fast-twich-glycolytic (FG) fiber diameter than control ones at 117 days and tended to have great diameter at 217 days. No differences in fast-twich- glycolytic-oxidative (FOG) and slow-twich-oxidative (SO) diameter and FG, FOG and SO percentage distribution were observed at 117 and 217 days. Despite the rbST treatment, there was a significant enlarge in SO and FOG fibers diameter, a tendency for increase in FG fibers diameter, an increase in SO and reduction in FG percentage distribution from 117 to 217 days. The somatotropin administration caused a greater hypertrophy of the white fast twitch muscle fibers in creep fed bull calves, but did not affect the percentage distribution of semitendinosus muscle fibers.
\end{abstract}

Key Words: creep feeding, growth, young bulls

\section{Introdução}

Ohormônio do crescimento (GH), ou somatotropina, influencia de forma coordenada o metabolismo, crescimento e a partição de nutrientes da maioria dos tecidos durante os períodos pré e pós-natal. $\mathrm{O}$ GH exerce grande impacto sobre a síntese de proteína corporal (Early et al., 1990); estudos têm evidenciado que o tratamento de animais domésticos com somatotropina exógena resulta em marcante crescimento do tecido muscular esquelético e redução na deposição de tecido adiposo (Boyd \& Bauman, 1991).

A avaliação dos efeitos da somatotropina bovina recombinante (rbST) no desenvolvimento das fibras

\footnotetext{
1 Parte da tese do primeiro autor.

2 Professor do curso de Zootecnia da Universidade São Marcos, São Paulo-SP. Bolsista da Fapesp (cervieri@bigfoot.com).

3 Professor Doutor do Departamento de Melhoramento e Nutrição Animal, FMVZ/UNESP/Botucatu, SP, Brasil (arrigoni@fca.unesp.br).

4 Professor do Departamento de Química e Bioquímica, Instituto de Biociências, UNESP/Botucatu, SP, Brasil (lachard@ibb.unesp.br).

5 Professor Titular do Departamento de Melhoramento e Nutrição Animal, FMVZ/UNESP/Botucatu, SP, Brasil (acsilveira@fca.unesp.br).

6 Professor Doutor do Departamento de Melhoramento e Nutrição Animal, FMVZ/UNESP/Botucatu, SP, Brasil (hnunes@fca.unesp.br).

7 Pós-Doutoranda do Departamento de Melhoramento e Nutrição Animal/FMVZ/UNESP/Botucatu, SP, Brasil (cludovico@fca.unesp.br).

8 Professora Ass. Doutora do Departamento de Morfologia, Instituto de Biociências, UNESP/Botucatu, SP, Brasil.
} 
musculares esqueléticas têm sido empregada para caracterizar a ação deste hormônio sobre o crescimento do tecido muscular em suínos (Solomon et al., 1994), novilhos (Ono et al., 1996) e bezerros (Moulton et al., 2000; Vann et al., 2001). Podem ser caracterizados três tipos de fibras musculares em bovinos: fibras brancas ou FG (glicolíticas de contração rápida) apresentam maior área, contração rápida e metabolismo anaeróbico; fibras vermelhas ou SO (oxidativas de contração lenta - apresentam pequena área, contração lenta e metabolismo aeróbico; e fibras intermediárias ou FOG (oxidativas-glicolíticas de contração rápida) possuem área intermediária, contração rápida e metabolismo aeróbico e glicolítico (Peter et al., 1972).

Em bezerros da raça Holandesa, a somatotropina produziu poucas alterações na frequência de distribuição e área das fibras do músculo Semimembranosus, mas propiciou aumento na área da seção transversal nas fibras do tipo FOG no músculo Tríceps bracchi (Maltin et al., 1990). Vestergaard et al. (1995), trabalhando com bezerras com 2,5 meses de idade recebendo15 mg de rbST por dia, não constataram efeito do hormônio sobre a distribuição dos três tipos de fibras do Longissimus dorsi, assim como Vann et al. (2001) observaram aumentos da área da seção transversal, frequência para as fibras do tipo FG e transformação de fibras do tipo FOG em fibras FG em bezerros tratados com rbST e suplementados em creep feeding.

Este estudo foi conduzido para se caracterizar morfologicamente as fibras musculares do músculo Semitendinosus quanto ao tipo, a frequência de distribuição e o diâmetro, mediante administração de rbST, em bezerros mestiços Angus-Nelore suplementados em creep feeding até a desmama.

\section{Material e Métodos}

O experimento foi realizado na Fazenda Sant'Anna, localizada no município de Rancharia, SP, no período de novembro de 2000 a abril de 2001, utilizando-se 36 bezerros machos, 1/2Angus- 1/2Nelore com idade inicial de $63 \pm 17$ dias e pesando $76,8 \pm 14,7 \mathrm{~kg}$, filhos de mesmo touro Aberdeen Angus. Os animais foram criados em mesma área (30 ha), sob pastejo contínuo de Brachiaria decunbens, e foram suplementados com ração concentrada no sistema creep feeding. A ração contendo $20 \%$ de PB e $72 \%$ de NDT, formulada de acordo com as normas do NRC
(1996), foi fornecida ad libitum diariamente em cochos cobertos. Os bezerros foram distribuídos em dois tratamentos: 18 bezerros receberam $1,4 \mathrm{mg} / \mathrm{kg}$ de rbST (Boostin ${ }^{\circledR}$ ) a cada 14 dias e 18, solução salina na mesma dosagem (controle). Tanto o rbST quanto a solução salina foram aplicados na região da base da cauda em lados alternados, em injeção única por via subcutânea.

Para o acompanhamento do padrão de crescimento do tecido muscular esquelético, foram efetuadas duas amostragens do músculo Semitendinosus: a primeira, aos 117 dias de idade $(138 \pm 20 \mathrm{~kg}$ ), quando foram colhidas amostras de nove animais por tratamento por meio de biópsia, segundo técnica descrita por Dubowitz \& Brooke (1984), e a segunda, aos 217 dias (241 $\pm 24 \mathrm{~kg})$, quando foram abatidos cinco animais por tratamento, retirando-se amostra após procedimento de esfola da carcaça. O músculo Semitendinosus foi escolhido por sua localização anatômica e pela discreta cobertura de gordura, permitindo fácil acesso durante a biópsia e coleta da amostra no postmortem (Arrigoni et al., 1998).

Coletou-se aproximadamente $3,0 \mathrm{~g}$ de tecido na biópsia e 10,0 g no abate, sempre na porção central do músculo e do lado direito da carcaça. As amostras foram mantidas em temperatura ambiente por 20 minutos e, em seguida, foram processadas (retirada de um fragmento com aproximadamente $0,5 \mathrm{~cm}^{3}$, que foi imerso em nitrogênio líquido por um minuto e acondicionado em tubos plásticos) e congeladas em nitrogênio líquido.

As análises laboratoriais foram realizadas no Laboratório do Departamento de Morfologia-IBUNESP-Botucatu. As amostras foram retiradas do nitrogênio e transferidas para o micrótomo criostato a $-20^{\circ} \mathrm{C}$ (Keichert Jung, modelo CM 1800, Leica), onde várias séries de cortes histológicos com $10 \mathrm{~mm}$ foram obtidas e fixadas em lâmina. Os fragmentos musculares, para realização dos cortes, foram dispostos perpendicularmente em suportes metálicos do micrótomo criostato, utilizando-se o adesivo líquido OCT Tissue TEK (Optimal Critical Temperature Compound, Miles). Em seguida, as séries de cortes foram submetidas à técnica histoquímica, para verificação da atividade contrátil da ATPase miofibrilar, com pré-incubação ácida em pH 4,6 (Brooke \& Kaiser, 1970), para se proceder à diferenciação dos tipos de fibras musculares.

Para a nomenclatura das fibras, foi adotada a classificação de Peter et al. (1972), com identificação de três tipos de fibras musculares: SO, FOG e FG. 
Para os cálculos das freqüências e do menor diâmetro das fibras, foram obtidos ao campos em cada lâmina, totalizando de 700 a 900 fibras analisadas por animal. Para a leitura dos campos, utilizou-se microscópio ótico (Olympus, ocular 12,5X e objetiva 20X) acoplado ao analisador de imagens de microscopia ótica Leica e a um computador com programa de análise de imagens (Image-Pro Plus 4.5.0.27).

Foram avaliados os efeitos da administração de rbST, da idade e da interação tratamento $\mathrm{x}$ idade sobre o diâmetro e a frequência das fibras musculares. $\mathrm{O}$ delineamento experimental utilizado foi o inteiramente casualizado e os resultados foram submetidos à análise de variância, pelo procedimento GLM do programa computacional Statistical Analysis System 6.12 (SAS, 1996).

\section{Resultados e Discussão}

Foram identificados, pela técnica histoquímica empregada (m-ATPase ácida, $\mathrm{pH} 4,6$ ), os três tipos de fibras musculares, com distribuição em mosaico; as fibras do tipo SO apresentaram reatividade forte (coloração escura), enquanto as fibras FG reagiram moderadamente (coloração intermediária) e as do tipo FOG reagiram de maneira mais fraca (coloração mais clara) (Peter et al., 1972).

Constam, na Tabela 1, as médias das freqüências de distribuição e diâmetros dos três tipos de fibras musculares avaliadas aos 117 dias de idade. Os bezerros que receberam rbST apresentaram diâmetro $15,3 \%$ maior $(\mathrm{P}<0,05)$ para as fibras $\mathrm{FG}$ que os animais controle, não havendo diferença significativa quanto ao diâmetro das fibras SO e FOG e às frequências das fibras SO, FOG e FG $(\mathrm{P}>0,05)$.

$\mathrm{Na}$ avaliação realizada aos 217 dias (Tabela 2), houve tendência de aumento de $12,4 \%$ no diâmetro das fibras FG $(\mathrm{P}<0,10)$, não havendo diferença significativa para o diâmetro das fibras dos tipos SO e FOG e para as frequências de distribuição de SO, FOG e FG (P>0,05). Maltin et al. (1990), analisando as fibras de dois grupos musculares de bezerros holandeses abatidos aos 116 dias de idade, suplementados ou não com extrato de pituitária (3,5 mg de bST/dia), não observaram diferenças quanto À área e frequência de distribuição dos três tipos de fibras no músculo Semimembranosus e Triceps bracchi, com apenas discreto aumento da área das fibras FOG no músculo tríceps bracchi nos animais tratados.

Vestergaard et al. (1995), trabalhando com bezerras holandesas, não verificaram efeito da somatotropina sobre a distribuição dos tipos de fibras no músculo Longissimus dorsi. Quanto à área, os autores relataram que, apenas para as fibras do tipo SO, houve tendência de aumento. Entretanto, Vann et al. (2001) econtraram maior área e aumento da frequência para

Tabela 1 - Médias dos diâmetros e freqüências de distribuição das fibras musculares do músculo Semitendinosus avaliadas na biópsia aos 117 dias

Table 1 - Semitendinosus muscle fibers diameter and frequence means by biopsy at 117 days

\begin{tabular}{|c|c|c|c|c|}
\hline \multirow[b]{2}{*}{$\begin{array}{l}\text { Parâmetro } \\
\text { Trait }\end{array}$} & \multicolumn{2}{|c|}{$\begin{array}{l}\text { Tratamento } \\
\text { Treatment }\end{array}$} & \multirow[t]{2}{*}{$\mathrm{CV}^{1}(\%)$} & \multirow[t]{2}{*}{$\begin{array}{l}\text { Significância } \\
P \text {-value }\end{array}$} \\
\hline & $\begin{array}{l}\mathrm{rbST} \\
r b S T\end{array}$ & $\begin{array}{c}\text { Controle } \\
\text { Control } \\
\end{array}$ & & \\
\hline $\begin{array}{l}\text { Diâmetro } \mathrm{SO}, \mathrm{mm} \\
\text { SO diameter, } \mathrm{mm}\end{array}$ & 28,19 & 27,89 & 8,6 & $\mathrm{NS}^{2}$ \\
\hline $\begin{array}{l}\text { DiâmetroFOG, } \mathrm{mm} \\
\text { FOG diameter, } \mathrm{mm}\end{array}$ & 31,05 & 30,58 & 9,8 & NS \\
\hline $\begin{array}{l}\text { Diâmetro } \mathrm{FG}, \mathrm{mm} \\
\text { FG diameter, } \mathrm{mm}\end{array}$ & 47,42 & 41,11 & 10,4 & $\mathrm{P}<0,05$ \\
\hline $\begin{array}{l}\text { Frequência } \mathrm{SO}, \% \\
\text { SO frequence, } \%\end{array}$ & 15,7 & 14,4 & 18,6 & NS \\
\hline $\begin{array}{l}\text { Frequência FOG, } \% \\
\text { FOG frequence, } \%\end{array}$ & 21,4 & 19,2 & 23,3 & NS \\
\hline $\begin{array}{l}\text { Frequência } \mathrm{FG}, \% \\
\text { FG frequence, \% }\end{array}$ & 62,9 & 66,4 & 9,0 & NS \\
\hline
\end{tabular}

1 Coeficiente de variação (Coefficient of variation).

2 NS - não-significativo (NS - not significant). 
Tabela 2 - Médias dos diâmetros e freqüências de distribuição das fibras musculares do músculo Semitendinosus avaliadas no abate aos 217 dias

Table 2 - Semitendinosus muscle fibers diameter and frequence means at slaughter at 217 days

\begin{tabular}{|c|c|c|c|c|}
\hline \multirow[b]{2}{*}{$\begin{array}{l}\text { Parâmetro } \\
\text { Trait }\end{array}$} & \multicolumn{2}{|c|}{$\begin{array}{c}\text { Tratamento } \\
\text { Treatment }\end{array}$} & \multirow[t]{2}{*}{$\mathrm{CV}^{1}(\%)$} & \multirow[t]{2}{*}{$\begin{array}{c}\text { Significância } \\
P \text {-value }\end{array}$} \\
\hline & $\begin{array}{l}\mathrm{rbST} \\
r b S T\end{array}$ & $\begin{array}{l}\text { Controle } \\
\text { Control }\end{array}$ & & \\
\hline $\begin{array}{l}\text { Diâmetro } \mathrm{SO}, \mathrm{mm} \\
\text { SO diameter, } \mathrm{mm}\end{array}$ & 32,66 & 32,81 & 13,0 & $\mathrm{NS}^{2}$ \\
\hline $\begin{array}{l}\text { DiâmetroFOG, } \mathrm{mm} \\
\text { FOG diameter, } \mathrm{mm}\end{array}$ & 41,54 & 37,40 & 12,3 & NS \\
\hline $\begin{array}{l}\text { Diâmetro FG, } \mathrm{mm} \\
\text { FG diameter, } \mathrm{mm}\end{array}$ & 56,32 & 45,66 & 18,7 & $P<0,10$ \\
\hline $\begin{array}{l}\text { Frequência } \mathrm{SO}, \% \\
\text { SO frequence, } \%\end{array}$ & 21,8 & 19,0 & 17,4 & NS \\
\hline $\begin{array}{l}\text { Frequência FOG, } \% \\
\text { FOG frequence, } \%\end{array}$ & 23,3 & 25,4 & 21,6 & NS \\
\hline $\begin{array}{l}\text { Frequência } \mathrm{FG}, \% \\
\text { FG frequence, } \%\end{array}$ & 54,9 & 55,6 & 14,7 & NS \\
\hline
\end{tabular}

1 Coeficiente de variação (Coefficient of variation).

2 NS - não-significativo (NS - not significant).

fibras FG nos bezerros tratados com rbST $(0,09 \mathrm{mg} /$ $\mathrm{kg} / \mathrm{dia}$ a cada 14 dias) em relação ao grupo controle, durante a fase de cria com suplementação em creep feeding. Os autores atribuíram a maior musculosidade apresentada pelos animais suplementados com rbST à maior taxa de transformação das fibras do tipo FOG para FG, que não foi observada no presente estudo.

Moulton et al. (2000) descreveram resultado semelhante ao de Vann et al. (2001), com redução da frequência de fibras FOG e aumento da porcentagem de fibras FG nos bezerros tratados com rbST $(2,2 \mathrm{mg}$ / $\mathrm{kg} /$ dia a cada 14 dias), não havendo efeito sobre a área dos três tipos de fibras. Moreira (2002) não verificou diferença quanto aos diâmetros das fibras SO, FOG e FG entre os tratamentos controle e rbST $(0,15 \mathrm{mg} / \mathrm{kg} / \mathrm{dia}$ a cada $14 \mathrm{dias})$ nas avaliações realizadas aos 150 e 210 dias em bezerros machos Simbrasil suplementados em creep feeding. Morais (1999) concluiu que a somatotropina (500 mg de rbST a cada 28 dias) provocou modulação das fibras musculares de contração lenta para rápida em novilhos cruzados com a raça Nelore confinados após a desmama, sem entretanto causar efeito sobre as áreas das mesmas.

Fatores inerentes ao grupo genético e suas características de crescimento e à idade de abate são variáveis relevantes para o estudo do tecido muscular quanto à freqüência de distribuição e ao diâmetro de suas fibras. Desta forma, as variações encontradas nos efeitos da somatotropina sobre o desenvolvimento das fibras musculares podem estar associadas ao grupo genético e à idade em que foi feita a avaliação. Johnston et al. (1975), Spindler et al. (1980), Tatum et al. (1990) e Wegner et al. (2000) relataram a existência de diferenças marcantes quanto à freqüência e crescimento dos três tipos de fibras musculares em bovinos de diferentes raças de origem européia avaliados em diferentes idades.

$O$ incremento da massa muscular pode ser obtido principalmente pelo aumento do número de fibras musculares, aumento da área das fibras ou transformação de fibras menores e oxidativas em fibras maiores e glicolíticas (Wegner et al., 2000). A transformação dos tipos de fibras musculares é, segundo Ashmore et al. (1972), um dos fatores responsáveis pelo aumento do volume muscular, considerando-se que a conversão de fibras de menor diâmetro do tipo FOG em fibras maiores do tipo FG, ocorre em animais selecionados para maior rendimento de tecido magro. A modulação de FOG para FG seria então uma maneira efetiva de promover o crescimento muscular (Dransfield \& Sosnicki, 1999). Entretanto, neste estudo, a frequência das fibras FOG e FG não diferiu entre os tratamentos nas duas idades avaliadas, indicando não ter havido modulação. O efeito do rbST manifestou-se sobre a hipertrofia das fibras FG, potencializando seu crescimento, como também foi observado por Solomon et al. (1994), em suínos, e Vann et al. (2001), em bezerros.

$\mathrm{O}$ estímulo do GH à síntese protéica, ao cresci- 
mento e à distribuição das miofibras parece ser músculo dependente, não havendo efeito uniforme em todos os grupos musculares, o que, de certa maneira, contribui para as discrepâncias encontradas entre resultados. Pell \& Bates (1987) sugeriram que músculos com predomínio de fibras oxidativas ou vermelhas respondem mais à agentes externos partidores. Em novilhos, Elsasser et al. (1998) observaram aumento de peso e maior taxa de deposição protéica diária nos músculos Rectus femoris e Triceps brachii mediante suplementação com $\mathrm{rbST}(0,1 \mathrm{mg} / \mathrm{kg} / \mathrm{dia})$ em relação ao controle, sendo que o Supraspinatus, Psoas major e Semitendinosus não apresentaram alteração de peso ou mudança na taxa de deposição protéica. Ono et al. (1996) avaliaram os efeitos de dois promotores de crescimento (Synovex-S ${ }^{\circledR}$ e rbST) sobre a composição das fibras musculares de seis músculos em novilhos. A administração exógena de somatotropina ocasionou decréscimo na porcentagem de fibras do tipo FOG de $35,5 \%$ para $27,5 \%$ e acréscimo nas fibras FG de $42 \%$ para $49,5 \%$ no músculo Rectus femoris. Além disso, os animais tratados apresentaram maiores áreas nos três tipos de fibras (FG, FOG e SO) no músculo Psoas major e maior área para as fibras SO no Supraspinatus e Semitendinosus. Trabalho semelhante foi desenvolvido por Solomon et al. (1994) em suínos, no qual a suplementação com somatotropina não influenciou a distribuição das fibras SO, FOG e FG nos músculos Longissimus dorsi, Semimembranosus e Triceps brachii, porém propiciou aumento da porcentagem das fibras FOG e redução das FG no Semitendinosus. Os autores observaram aumento da área nas fibras FOG e FG nos quatro músculos estudados e aumento da área das fibras SO apenas no Semitendinosus.

Os efeitos da idade (Tabela 3) e da interação entre idade e aplicação de rbST foram apresentados como alterações relativas, expressas em porcentagem, comparando-se a evolução do diâmetro e a frequiência de cada tipo de fibra entre as duas idades dentro dos respectivos tratamentos (Figuras 1 e 2). Houve efeito significativo da idade para o diâmetro das fibras $\mathrm{SO}$ e FOG $(\mathrm{P}<0,05)$ e tendência para o diâmetro das fibras FG $(\mathrm{P}<0,10)$. Para os três tipos de fibras, ocorreu aumento do diâmetro entre 117 e 217 dias, não havendo efeito de interação idade $\mathrm{x}$ tratamento. A idade interferiu significativamente nas frequiências de distribuição das fibras $\mathrm{SO}$ e $\mathrm{FG}(\mathrm{P}<0,05)$, elevando a porcentagem de fibras $\mathrm{SO}$ e reduzindo a porcentagem de fibras FG. Quanto à interação, apenas para as fibras FOG houve efeito significativo $(\mathrm{P}<0,05)$.

As alterações decorrentes do crescimento para determinado músculo podem ser avaliadas pela mensuração da freqüência de distribuição e pela área

Tabela 3 - Efeito da idade sobre o diâmetro e a freqüência das fibras musculares do músculo Semitendinosus

Table 3 - Age effect on Semitendinosus muscle fibers diameter and percentage frequence

\begin{tabular}{|c|c|c|c|c|}
\hline \multirow[b]{2}{*}{$\begin{array}{l}\text { Parâmetro } \\
\text { Trait }\end{array}$} & \multicolumn{2}{|c|}{$\begin{array}{l}\text { Idade } \\
\text { Age }\end{array}$} & \multirow[t]{2}{*}{$\mathrm{CV}^{1}(\%)$} & \multirow[t]{2}{*}{$\begin{array}{c}\text { Significância } \\
P \text {-value }\end{array}$} \\
\hline & 117 & 217 & & \\
\hline $\begin{array}{l}\text { Diâmetro } \mathrm{SO}, \mathrm{mm} \\
\text { SO diameter, } \mathrm{mm}\end{array}$ & 28,42 & 32,75 & 12,9 & $P<0,05$ \\
\hline $\begin{array}{l}\text { Diâmetro FOG, } \mathrm{mm} \\
\text { FOG diameter, } \mathrm{mm}\end{array}$ & 31,55 & 39,47 & 16,5 & $P<0,05$ \\
\hline $\begin{array}{l}\text { Diâmetro FG, } \mathrm{mm} \\
\text { FG diameter, } \mathrm{mm}\end{array}$ & 45,63 & 50,99 & 18,0 & $P<0,10$ \\
\hline $\begin{array}{l}\text { Frequência } \mathrm{SO}, \% \\
\text { SO frequence, } \%\end{array}$ & 14,7 & 20,4 & 24,2 & $P<0,05$ \\
\hline $\begin{array}{l}\text { Frequência FOG, } \% \\
\text { FOG frequence, } \%\end{array}$ & 22,0 & 24,4 & 22,3 & $\mathrm{NS}^{2}$ \\
\hline $\begin{array}{l}\text { Frequência } \mathrm{FG}, \% \\
\text { FG frequence, } \%\end{array}$ & 63,2 & 55,2 & 13,7 & $P<0,05$ \\
\hline
\end{tabular}

1 Coeficiente de variação (Coefficient of variation).

2 NS - não-significativo (NS- not significant). 


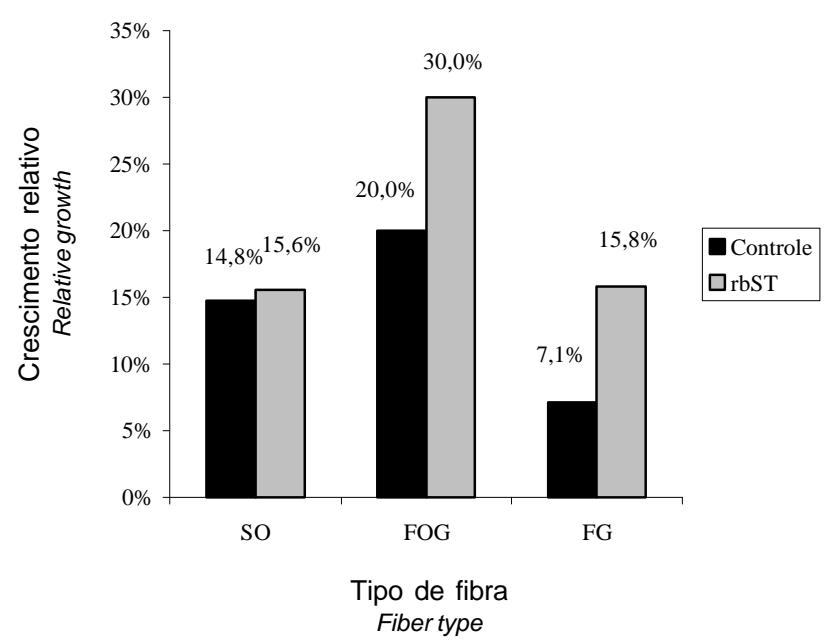

Figura 1 - Crescimento relativo do diâmetro das fibras musculares entre 117 e 217 dias.

Figure 1 - Relative growth of diameter in muscle fibers from 117 to 217 days of age.

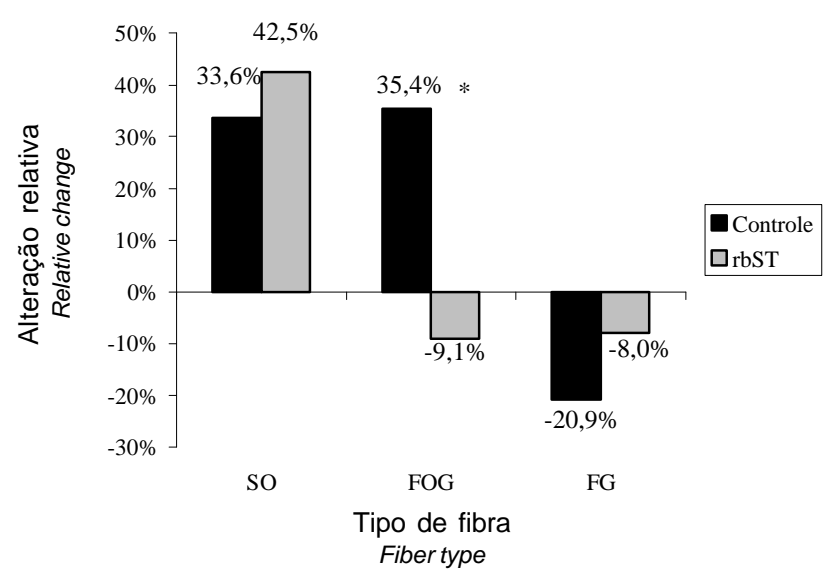

${ }^{*} \mathrm{P}<0,05$, efeito de interação idade $x$ tratamento.

Figura 2 - Alteração relativa das freqüências de distribuição das fibras musculares entre 117 e 217 dias.

Figure 2 - Relative change of percentage distribution in muscle fibers from 117 to 217 days of age.

ocupada pelos diferentes tipos de fibras (Spindler et al., 1980), uma vez que a área das fibras musculares eleva-se com o decorrer da idade e com o avanço do peso vivo (Solomon et al., 1986). O aumento de diâmetro apresentado nas fibras musculares $(15,2 \%$ para SO, 25,1\% para FOG e $11,7 \%$ para FG) demonstra a intensa hipertrofia muscular que ocorre durante o crescimento pós-natal.
Wegner et al. (2000) descrevem que entre dois e seis meses de idade, ocorre a maior taxa de aumento na área da fibras do músculo Semitendinosus em bovinos de raças européias, o que está de acordo com os relatos de Spindler et al. (1980), qe observaram significativo aumento da área dos três tipos de fibras em bezerros de 28 a 224 dias de idade. Jurie et al. (1995), trabalhando com bezerros Limousin de 1 a 6 meses de idade, verificaram aumento de $258 \%$ da área média dos três tipos de fibras do músculo Semitendinosus.

Os resultados deste estudo estão de acordo com os apresentados por Jurie et al (1995) e Wegner et al. (2000), que verificaram que o músculo Semitendinosus apresenta menor proporção de fibras SO de que as fibras FOG e FG em bezerros mais jovens. Entretanto, estes autores constataram redução da freqüência das fibras FOG e aumento da percentagem das fibras FG, entre 1 e 12 meses de idade, caracterizando este período de crescimento como de incremento do metabolismo glicolítico no músculo Semitendinosus, em função da transformação das fibras FOG em FG. As alterações das frequências das fibras em função da idade observadas neste estudo (aumento da porcentagem de SO e redução da porcentagem de FG) foram inesperadas e diferem das transformações registradas em ensaios anteriores, não havendo incremento do metabolismo glicolítico no músculo avaliado. Uma possível explicação seriam as diferenças quanto à posição de coleta das amostras de músculo. A freqüência de distribuição dos tipos de fibras no interior de um mesmo músculo tem se revelado variável (Armstrong \& Phelps, 1984) e segundo Pearson \& Young (1989), existe, de maneira geral, maior concentração de fibras oxidativas em regiões mais profundas do músculo e maior distribuição de fibras glicolíticas na porção superficial. Neste sentido, aos 117 dias, as amostras foram colhidas por biópsia, em uma porção mais superficial do músculo. Aos 217 dias, foram colhidas amostras no abate, e, em virtude da facilidade de retirada, colheram-se amostras maiores e possivelmente de regiões mais profundas do músculo, onde a concentração de fibras oxidativas é naturalmente maior, o que talvez possa ter interferido na freqüência de distribuição.

Quanto à interação entre idade e tratamento, apenas a freqüência das fibras FOG apresentou efeito interativo, com aumento da porcentagem nos animais controle e redução nos suplementados com rbST 
(Figura 2). Nas fibras SO, ocorreu aumento relativo da freqüência nos dois grupos e, para as fibras FG, redução, ambos não-significativos. Esse comportamento possivelmente esteja associado ao efeito da posição de coleta, uma vez que a redução do metabolismo glicolítico de um músculo em animais tratados com rbST não tem sido comumente observada, com exceção dos resultados apresentados por Ayling et al. (1989), que verificaram aumento da freqüência de fibras do tipo I (SO) nos músculos Soleus e Extensor digiturium longus de ratos hipofisectomisados tratados com GH humano. Solomon et al. (1994) também relataram maior freqüência de fibras FOG e redução da freqüência de fibras FG no músculo Semitendinosus em suínos tratados com rpST na dosagem de $0,1 \mathrm{mg} / \mathrm{kg} / \mathrm{dia}$.

Vann et al. (2001) não verificaram interações entre idade e suplementação com rbST nas freqüências de distribuição das fibras SO, FOG e FG, no período entre 100 e 206 dias de idade, sendo que, numericamente, houve redução de SO (30\%) e FOG (16\%) no grupo controle. Nos animais tratados, a redução foi de $23 \%$ nas SO e de $21 \%$ nas FOG. Além disso, os autores encontraram interações significativas para a área das fibras SO e FOG, com maior crescimento relativo nos bezerros que receberam rbST. Neste estudo, apesar de não-significativo, houve expressivo crescimento relativo do diâmetro nas fibras do tipo FOG e FG nos animais que receberam rbST em relação ao controle (Figura 1).

O crescimento do tecido muscular esquelético é caracterizado por aumentos na área e no comprimento dos três tipos de fibras musculares, seja por adição ou elongamento dos sarcômeros (Swatland, 1978). Pela análise realizada na seção transversal do músculo Semitendinosus, por meio da mensuração do menor diâmetro das fibras, foi possível constatar o efeito hipertrófico da somatotropina sobre a área das fibras FG, as quais naturalmente apresentam maior área que as dos tipos SO e FOG, caracterizando a ação do GH sobre o metabolismo anaeróbico do músculo, como reportado anteriormente por outros pesquisadores.

O significativo aumento do diâmetro para os três tipos de fibras musculares evidenciou a intensa hipertrofia muscular que ocorre em animais jovens no período pré-desmama.

\section{Conclusões}

A utilização da somatotropina exógena em bezerros durante a fase de cria propiciou maior hipertrofia das fibras brancas glicolíticas de contração rápida no músculo Semitendinosus, resultado não observado nas fibras com metabolismo oxidativo e oxidativo-glicolítico.

A composição do músculo não foi modificada pela somatotropina, uma vez que as freqüências de distribuição dos três tipos de fibras foram semelhantes entre os tratamentos testados.

\section{Agradecimento}

À FAPESP (Fundação de Amparo à Pesquisa do Estado de São Paulo), pela bolsa de estudos concedida.

\section{Literatura Citada}

ARMSTRONG, R.B.; PHELPS, R.D. Muscle fiber type composition of rat hindlimb. American Journal of Anatomy, v.171, n.2, p.259-272, 1984.

ARRIGONI, M.D.B.; VIEIRA, P.F.; SILVEIRA, A.C. et al. Estudo dos efeitos da restrição alimentar nas características das fibras musculares de bovinos jovens confinados. Pesquisa Agropecuária Brasileira, v.33, n.3, p.1121$1127,1998$.

ASHMORE, C.R.; TOMPKINS, G.; DOERR, L. Postnatal development of muscle fiber types in domestic animals. Journal of Animal Science, v.34, n.1, p.37-41, 1972.

AYLING, C.M.; MORELAND, B.H.; ZANELLI, J.M. et al. Human growth hormone treatment of hypophysectomized rats increases the proportion of type-1 fibers in skeletal muscle. Journal of Endocrinology, v.123, n.4, p.429-435, 1989.

BOYD, R.D.; BAUMAN, D.E. Mechanisms of action for somatotropin in growth. In: BOYD, R.D.; BAUMAN, D.E. (Eds.) Animal growth regulation. New York: Pleum Press, 1991, p. 257-293.

BROOKE, M.H.; KAISER, K. Muscle fiber type: How many and what kind? Archives of Neurology, v.23, n.2, p.369379,1970 .

DRANSFIELD, E.; SOSNICKI, A.A. Relationship between muscle growth and poultry meat quality. Poultry Science, v.78, n.3, p.743-746, 1999.

DUBOWITZ, V.; BROOKE, M. Muscle biopsy. London: Saunders, 1984. 472p.

EARLY, R.J.; McBRIDE, B.W.; BALL, R.O. Growth and metabolism in somatotropin-treated steers: III. Protein synthesis and tissue energy expenditures. Journal of Animal Science, v.68, n.12, p.4153-4166, 1990.

ELSASSER, T.H.; RUMSEY, T.S.; KAHL, S.M. et al. Effects of Synovex-S and recombinant bovine growth hormone (Somavubove) on growth responses of steers: III. Muscle 
growth and protein responses. Journal of Animal Science, v.76, n.9, p.2346-2353, 1998.

JOHNSTON, D.M.; STEWART, D.F.; MOODY, W.G. et al. Effect of breed and time on feed on the size and distribution of beef muscle fiber types. Journal of Animal Science, v.40, n.3, p.613-620, 1975.

JURIE, C., ROBELIN, J., PICARD, B. et al. Post-natal changes in biological characteristics of semitendinosus muscle in male Limousin cattle. Meat Science, v.41, n.1, p.125-135, 1995.

MALTIN, C.A.; DELDAY, S.M.; INNES, G.M. et al. Effects of bovine pituitary growth hormone alone or in combination with the b-agonist clenbuterol on muscle growth and composition in veal calves. British Journal of Nutrition, v.63, n.3, p.535-545, 1990.

MORAIS, J.P.G. Rendimento de cortes e características das fibras musculares de bovinos superprecoces, com aplicação da somatotropina bovina recombinante. Botucatu: Universidade Estadual Paulista, 1999. 51p. Tese (Doutorado em Produção e Nutrição Animal) - Universidade Estadual Paulista, 1999.

MOREIRA, P.S.M. Desempenho produtivo em bezerros lactentes: efeitos da somatotropina bovina recombinante (rbST) sobre o tecido muscular e os níveis de hormônios tireoideanos (T3 e T4) e IGF-1. Botucatu: Universidade Estadual Paulista, 2002. 118p. Tese (Doutorado em Ciências Biológicas) - Universidade Estadual Paulista, 2002.

MOULTON, K.E.; ALTHEN, T.G.; WILLIANS, A.R. Effects of recombinant bovine somatotropin (rbST) and nutrition on growth and muscle fiber profiles in early-weaned beef steers Journal of Animal Science, v.78, p.143 (Supl.1) (Abstr.), 2000.

NATIONAL RESEARCH COUNCIL - NRC. Nutrient requirements of beef cattle. 7.ed. Washington, D.C.: National Academy Press, 1996. 242p.

ONO, Y.; SOLOMON, M.B.; ELSASSER, T.H. et al. Effects of Synovex-S and recombinant bovine growth hormone (Somavubove) on growth responses of steers: II. Muscle Morphology and proximate composition of muscles. Journal of Animal Science, v.74, n. 12, p.2929-2934, 1996.

PEARSON, A.M.; YOUNG, R.B. Skeletal muscle fibers. In: PEARSON, A.H.; YOUNG, R.B. (Eds.) Muscle and meat biochemistry. 1.ed. San Diego: Academic Press, 1989. p.235-265.

PETER, J.B.; BARNARD, R.J.; EDGERTON, V.R. Metabolic profiles of three fiber types of skeletal muscle in Guinea pig and rabbits. Biochemistry, v.11, n.10, p.2672-2633, 1972.
PELL, J.M.; BATES, P.C. Collagen and non-collagen protein turnover in skeletal muscle of growth hormone-treated lambs. Journal of Endocrinology, v.115, n.1, p.R1-R4. 1987.

STATISTICAL ANALYSES SYTEM - SAS. Sas user's guide. 5.ed. Cary: 1996. 956p.

SPINDLER, A.A.; MATHIAS, M.M.; CRAMER, D.A. Growth changes in bovine muscle fiber types as influenced by breed and sex. Journal of Food Science, v.45, n. 1, p.29-31, 1980.

SOLOMON, M.B.; WEST, R.L.; HENTGES, J.F. Growth and muscle development characteristics of purebred Angus and Brahman bulls. Growth, v.50, n.1, p.51-67, 1986.

SOLOMON, M.B.; CAPERNA, T.J.; MROZ, R.J. et al. Influence of dietary protein and recombinant porcine somatotropin administration in young pigs: III. Muscle fiber morphology and shear-force. Journal of Animal Science, v.72, n.3, p.615-621, 1994.

SWATLAND, H.J. Longitudinal growth and rate of new sarcomere formation in porcine muscle. Journal of Animal Science, v.46, n.1, p.118-124, 1978.

TATUM, J.D.; GRONEWALD, K.W.; SEIDEMAN, S.C. et al. Composition and quality of beef from steers sired by Piedmontese, Gelbvieh and Red Angus bulls. Journal of Animal Science, v.68, n.5, p.1049-1060, 1990.

VANN, R.C.; ALTHEN, T.G.; SOLOMON, M.B. et al. Recombinant bovine somatotropin (rbST) increases size and proportion of fast glycolytic muscle fibers in semitendinosus muscle of creep-fed steers. Journal of Animal Science, v.79, n.1, p.108-114, 2001.

VESTERGAARD, M.; PURUP, S.; HENCKEL, P. et al. Effects of growth hormone and ovariectomy on performance, serum hormones, insulin-like growth factor-binding proteins, and muscle fiber properties of prepubertal friesian heifers. Journal of Animal Science, v.73, n.12, p.3574-3584, 1995.

WEGNER, J.; ALBRECHT, E.; FIEDLER, I. et al. Growth- and breed-related changes of muscle fiber characteristics in cattle. Journal of Animal Science, v.78, n. 6, p.1485-1496, 2000.

Recebido em: 06/04/04 Aceito em: 24/01/05 